\title{
EXPERIMENTAL STUDIES ON MYOCARDIAL METABOLISM OF CARBOHYDRATE AND LIPID IN SURFACE-INDUCED DEEP HYPOTHERMIA
}

\author{
Hiroshi Shida, Masami Morimoto, Koichi Inokawa, \\ AND Jiro TSUgane
}

$\mathbf{I}^{\mathrm{N}}$ the open-heart surgery undergoing surfaceinduced deep hypothermia, especially in cooling period, metabolic acidosis resulting from lactacidemia is ordinarily observed. Moreover, it is supposed that the lactacidemia results from the anaerobic glycolysis due to the tissue hypoxia, and the disability to metabolize an acidic metabolite in the liver! Therefore, under these situations, it is conceivable that the investigation of the change of myocardial metabolism presents one of the criteria to evaluate hypothermia for open-heart surgery. This study was performed to investigate the myocardial metabolism of carbohydrate and lipid during hypothermia, measuring coronary arteriovenous difference of glucose, lactate, pyruvate, total fatty acid and NEFA, and pyruvate dehydrogenase. Moreover, the influence of high dose administration of corticosteroid and ATP upon the myocardial metabolism during hypothermia was also observed.

\section{MATERIALS AND METHODS}

Mongrel adult dogs were divided into 3 groups with 5 to 7 dogs in each group. In the first group, no drug was administered during hypothermia. In the second group, $2 \mathrm{mg} / \mathrm{kg}$ of dexamethason phosphate was administered intravenously, and in the third group, $10 \mathrm{mg} / \mathrm{kg}$ of ATP-Na $\mathrm{Na}_{2}$ was administered. The dogs were premedicated with

Key Words:

Carbohydrate metabolism

Lipid metabolism

Surface-induced deep hypothermia

Myocardial metabolism
$1 \mathrm{mg} / \mathrm{kg}$ of triflupromazine, pethidine, promethazine and $0.01 \mathrm{mg} / \mathrm{kg}$ of atropine. Anesthesia was induced with pentobarbital and maintained with ether $2.0-2.5 \mathrm{ml} / \mathrm{kg}$ and $100 \%$ oxygen in a closed system. After deep anesthesia was induced with ether, the dog was placed in an ice water bath to approximately $23^{\circ} \mathrm{C}$ in an average in esophageal temperature. The transfusion was made with $5 \mathrm{ml} / \mathrm{kg}$ of low molecular weight dextran or hydroxyethyl starch and $5 \mathrm{ml} / \mathrm{kg}$ of xylitol in the cooling phase? Arterial blood was taken from the ascending aorta and coronary venous blood was taken from coronary sinus by cannulation or direct puncture. Blood gas by Astrup's method, blood glucose by OTB method, blood lactate and pyruvate by enzymatic determination, 3 plasma total fatty acid and composition of total fatty acid by gas chromatography, 4 plasma NEFA, pyruvate dehydrogenase $^{6}$ and coronary blood flow by electromagnetic flowmeter were measured before cooling and as low as $23^{\circ} \mathrm{C}$. Myocardial oxygen consumption $(\mathrm{ml} / 100 \mathrm{~g} / \mathrm{min}$.) was represented as coronary blood flow $(\mathrm{ml}) \times$ coronary arteriovenous oxygen difference $\times 1 / 100$. Myocardial metabolism was evaluated by A-V difference ratio, indicating an uptake or a relase of substance.

\section{RESULTS}

1. Acid Base Balance.

Blood $\mathrm{pH}$ decreased significantly from 7.49 at $37^{\circ} \mathrm{C}$ to $7.23 \pm 0.21$ at $23^{\circ} \mathrm{C}$ in the group I $(p<0.05)$ and showed the same fashion to that of the group I in the group II and III.

(Received on June 5, 1976; Accepted on Fabruary 8, 1977)

Second Department of Surgery, Faculty of Medicine, Shinshu University, Matsumoto, Nagano, Japan

(Asahi 3-1-1, Matsumoto City, Nagano Prefecture, Japan) 


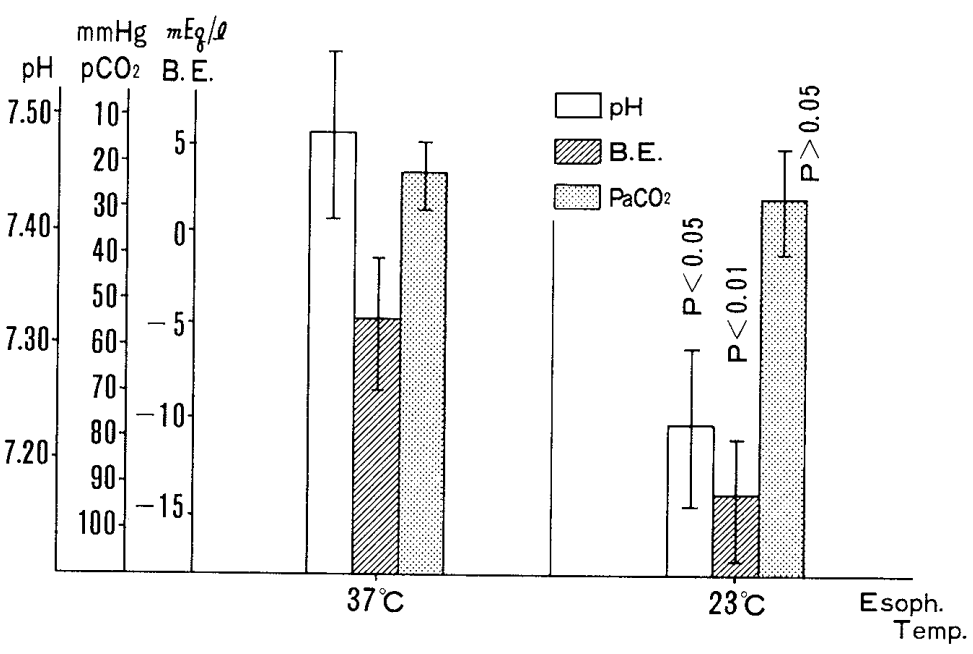

Fig.1. Acid-base balance of arterial blood in hypothermia in each group.

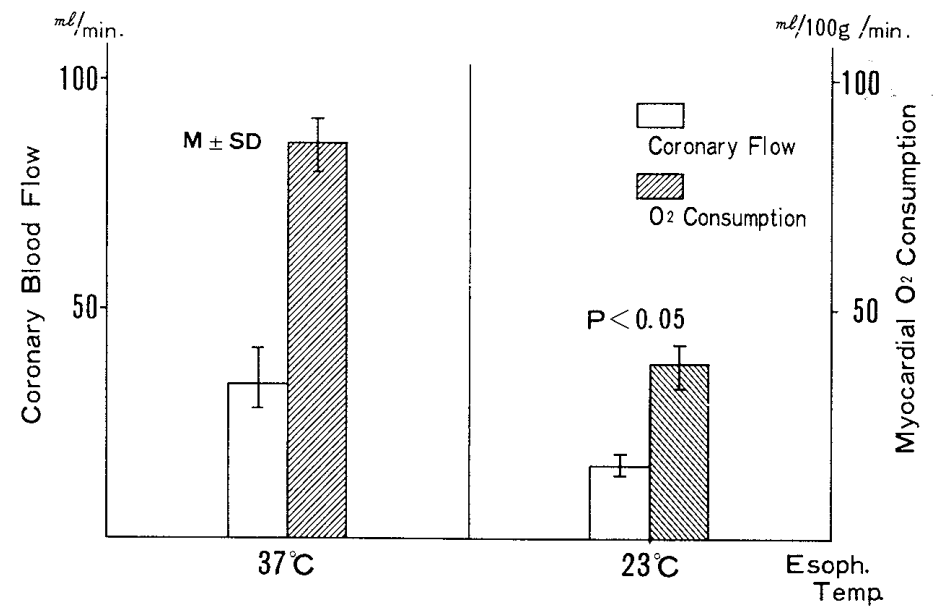

Fig.2. Coronary blood flow and myocardial oxygen consumption in hypothermia in group I.

Blood base excess also decreased significantly from $-5.2 \pm 3.6 \mathrm{mEq} / 1$ at $37^{\circ} \mathrm{C}$ to $-13.5 \pm 4.1$ at $23^{\circ} \mathrm{C}$ in the group I $(\mathrm{p}<0.01)$, showing the same change in the group II and III. Namely, metabolic acidosis developed during hypothermia in each group. On the other hand, no significant change was observed in $\mathrm{PaCO}_{2}$. In hypothermic anesthesia, $\mathrm{FiO}_{2}$ was $100 \%$ and ventilation was made in the fashion of hyperventilation (Fig. 1).

2. Coronary blood flow and myocardial oxygen consumption.

Coronary blood flow of $34.1 \pm 3.7 \mathrm{ml} / \mathrm{min}$. at $37^{\circ} \mathrm{C}$ was reduced to approximately half of the precooling level as $17.6 \pm 3.1 \mathrm{ml} / \mathrm{min}$. at the lowest temperature, showing a significant decrease $(\mathrm{p}<0.05)$. Myocardial oxygen consumption $(87.3 \mathrm{ml} / 100 \mathrm{~g} / \mathrm{min}$. in an average $)$ which was calculated by coronary blood flow and coronary arteriovenous oxygen difference also showed a significant decrease (38.6 in an average) at $23^{\circ} \mathrm{C}$ $(p<0.05)$, showing a reduction of approximately half of the precooling level. However, as mentioned above, in hypothermic ether anesthesia in a closed system, the $\mathrm{PaO}_{2}$ level was extremely high. Therefore, to obtain an absolute value of myocardial oxygen consumption, further investigations are necessary (Fig. 2).

3. Myocardial glucose metabolism

Blood glucose increased from $136 \pm 9 \mathrm{mg} / \mathrm{dl}$ to $182 \pm 15$ at $23^{\circ} \mathrm{C}$ in the group I, from $130 \pm$ 18 to $174 \pm 5$ in the group II, from $180 \pm 10$ to $210 \pm 15$ in the group III. Namely, blood glucose showed a significant increase $(\mathrm{p}<0.05)$ at $23^{\circ} \mathrm{C}$ in each group. Coronary arteriovenous glucose 

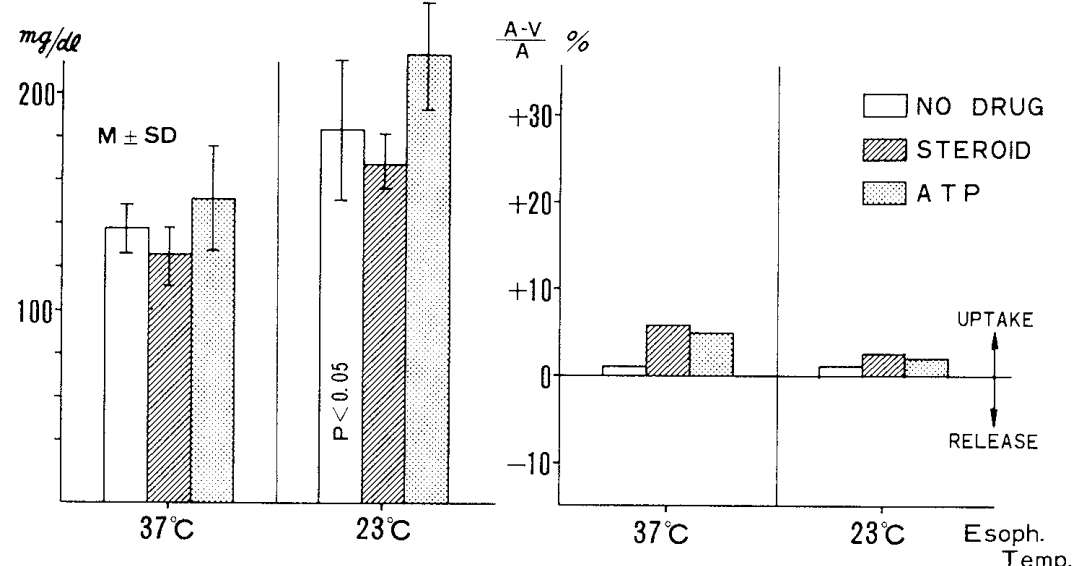

Fig.3. Blood glucose (left) and coronary arteriovenous (A-V) difference ratio of glucose (right) in hypothermia in each group.
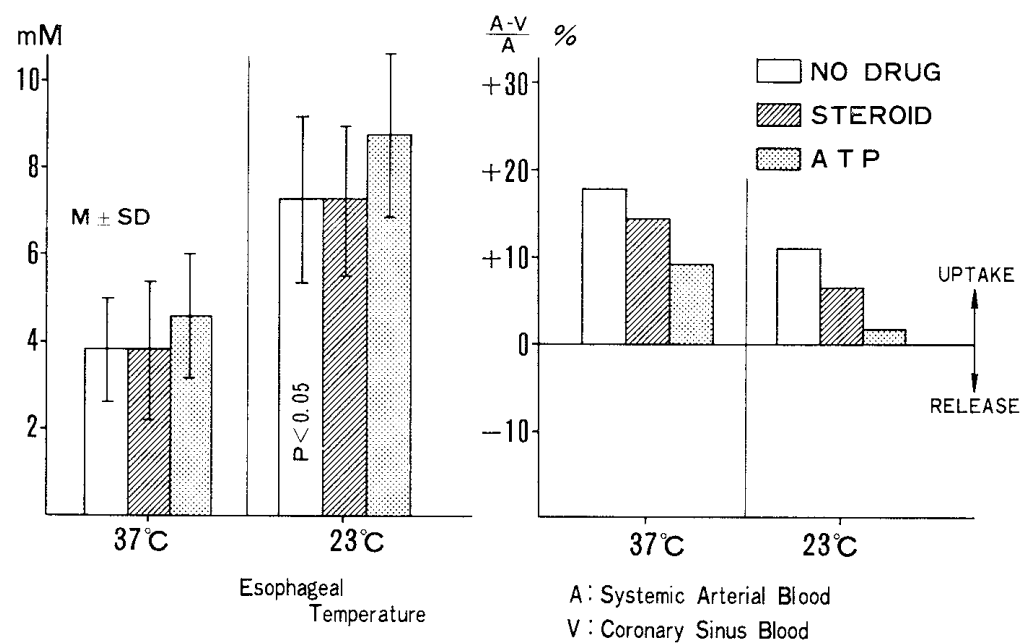

Fig.4. Blood lactate (left) and coronary A-V difference ratio of lactate (right) in hypothermia in each group.
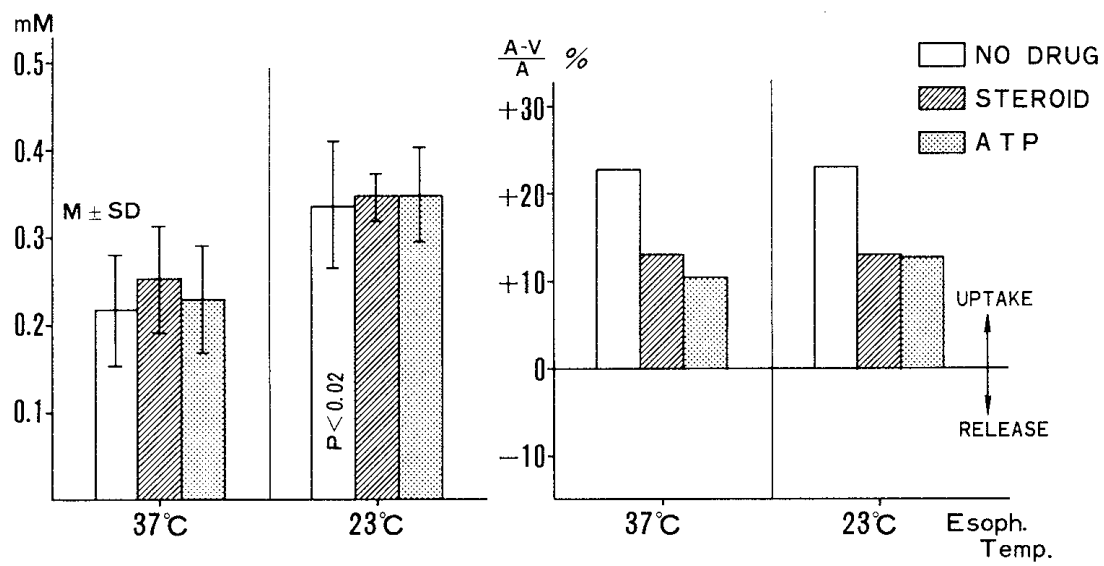

Fig.5. Blood pyruvate (left) and coronary A-V difference ratio of pyruvate (right) in hypothermia in each group. 


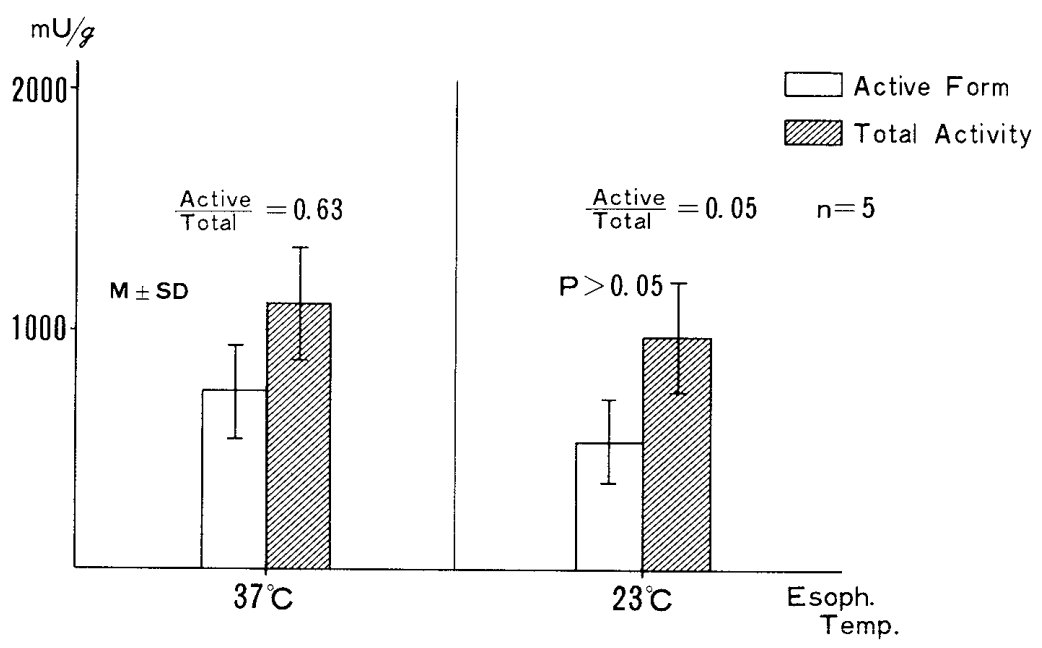

Fig.6. Pyruvate dehydrogenase of the cardiac muscle in hypothermia in group I.
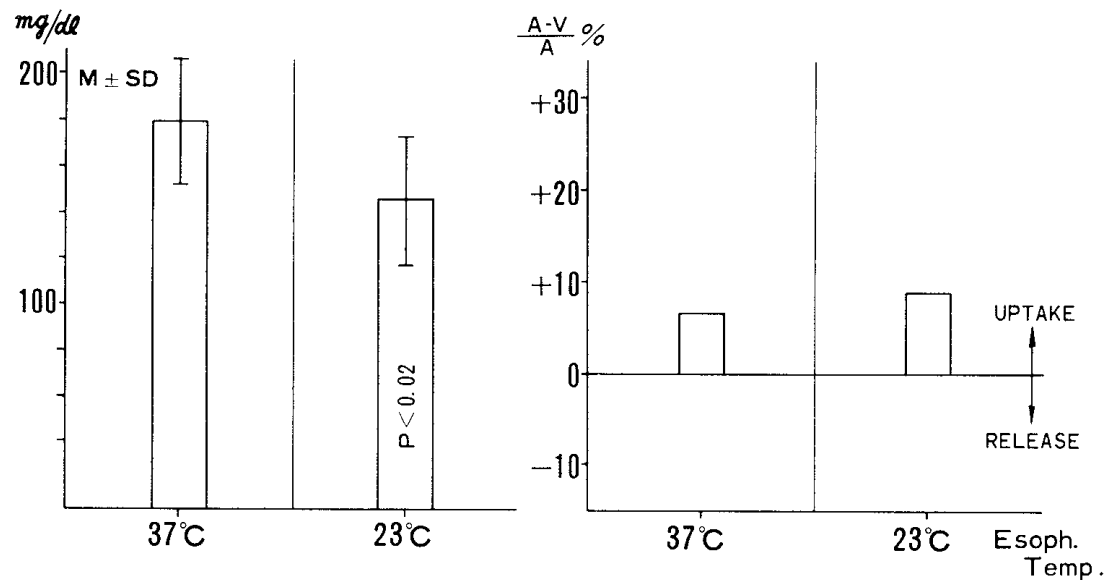

Fig.7. Plasma total fatty acid (left) and coronary A-V difference ratio of total fatty acid (right) in hypothermia in group I.

difference $(136 \pm 9-136 \pm 7 \mathrm{mg} / \mathrm{dl})$ was extremely low even at $37^{\circ} \mathrm{C}$, suggesting a very slight uptake in the cardiac muscle. As low as $23^{\circ} \mathrm{C}$, no significant change $(182 \pm 15-180 \pm 20)$ was observed. In the group II and III, the same findings were observed. There were no special differences between them. (Fig. 3).

4. Blood lactate

Blood lactate increased from $3.9 \pm 1.9 \mathrm{mM}$ at precooling to $7.3 \pm 2.7$ at $23^{\circ} \mathrm{C}$ in the group I, from $3.9 \pm 1.5$ to $7.2 \pm 2.8$ in the group II, from $4.6 \pm 2.2$ to $8.8 \pm 3.2$ in the group III. Namely, a significant increase of blood lactate was observed at $23^{\circ} \mathrm{C}$ in each group $(\mathrm{p}<0.05)$. While, coronary A-V lactate difference ratio was approximately $20 \%$ at the precooling, showing a definite utilization in the cardiac muscle. At $23^{\circ} \mathrm{C}$, the ratio decreased approximately half of the precooling level, however, it still showed a definite uptake in the cardiac muscle. In group II and III, the same findings were observed. Therefore, it seems that high dose exogenous corticosteroid and ATP do not influence on myocardial lactate metabolism (Fig. 4).

\section{Blood pyruvate}

Blood pyruvate increased from $0.22 \pm 0.16$ $\mathrm{mM}$ at precooling to $0.34 \pm 0.20$ at $23^{\circ} \mathrm{C}$ in the group I, from $0.27 \pm 0.15$ to $0.35 \pm 0.05$ in the group II, from $0.23 \pm 0.18$ to $0.35 \pm 0.15$ in the group III. Namely blood pyruvate showed a significant increase $(p<0.02)$ at $23^{\circ} \mathrm{C}$ in each group as well as the change of lactate. From the aspect of myocardial pyruvate metabolism, coronary $\mathrm{A}-\mathrm{V}$ pyruvate difference ratio was more than $20 \%$ at the precooling, showing a definite utilization of pyruvate. As low as $23^{\circ} \mathrm{C}$, coronary 

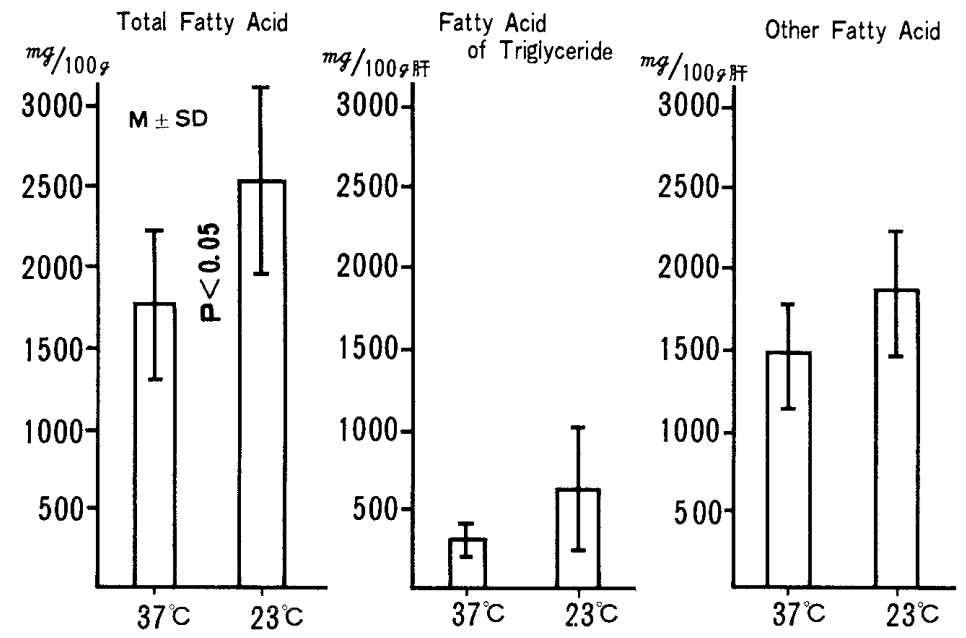

Fig.8. Fatty acid of the dog liver in hypothermia in group I.
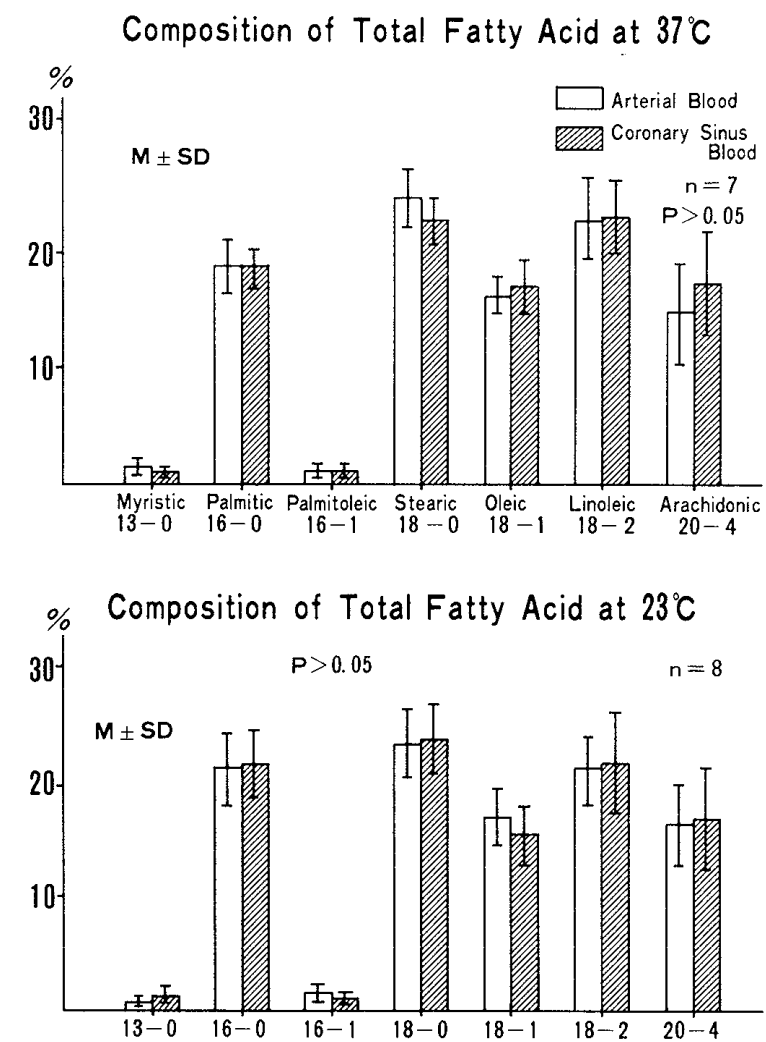

Fig.9. Composition of plasma total fatty acid in hypothermia in group I.

A-V pyruvate difference ratio showed the same value to that of precooling. This result suggests that pyruvate plays an important role as energy source in cardiac muscle during hypothermia. As for the influence of corticosteroid and ATP upon myocardial pyruvate metabolism, there were no special differences between each group (Fig. 5).

6. Pyruvate dehydrogenase
The active form of pyruvate dehydrogenase (PDH) in the cardiac muscle was $754 \pm 492 \mathrm{mU} / \mathrm{g}$ tissue at $37^{\circ} \mathrm{C}$ and $542 \pm 227$ at $23^{\circ} \mathrm{C}$ in the group I. The total activity was $1099 \pm 514$ at $37^{\circ} \mathrm{C}$ and $985 \pm 408$ at $23^{\circ} \mathrm{C}$. Namely, the active form PDH in the cardiac muscle showed a trend of decrease as low as $23^{\circ} \mathrm{C}$, and the total activity also showed the same finding as that of the active form. However, there was no statistical difference between them (Fig. 6).

7. Total fatty acid

Plasma total fatty acid showed a significant decrease $(\mathrm{p}<0.02)$ at $23^{\circ} \mathrm{C}$, changing $183 \pm 28$ $\mathrm{mg} / \mathrm{dl}$ at precooling to $149 \pm 28$ at $23^{\circ} \mathrm{C}$ in the group I (Fig. 7. left). As for the mechanism of decrease of plasma total fatty acid, as shown in Fig. 8, total fatty acid in the liver significantly increased as well as other fatty acid $(p<0.05)$. Therefore, it seemed that the accumulation of fatty acid in the liver during hypothermia played an important role. On the other hand, in the aspect of myocardial metabolism of total fatty acid, coronary A.V difference ratio showed less than $10 \%$ uptake at the precooling and as low as $23^{\circ} \mathrm{C}$, indicating no significant change (Fig. 7 . right).

8. Composition of total fatty acid

Compared with the composition of total fatty acid of coronary arterial blood and coronary sinus blood at $37^{\circ} \mathrm{C}$, there was no significant difference between them. While, as low as $23^{\circ} \mathrm{C}$, there was also no significant difference between that of coronary arterial blood and coronary sinus blood. Moreover, compared with the composition of total fatty acid in both coronary arterial blood and coronary sinus blood at $37^{\circ} \mathrm{C}$ 

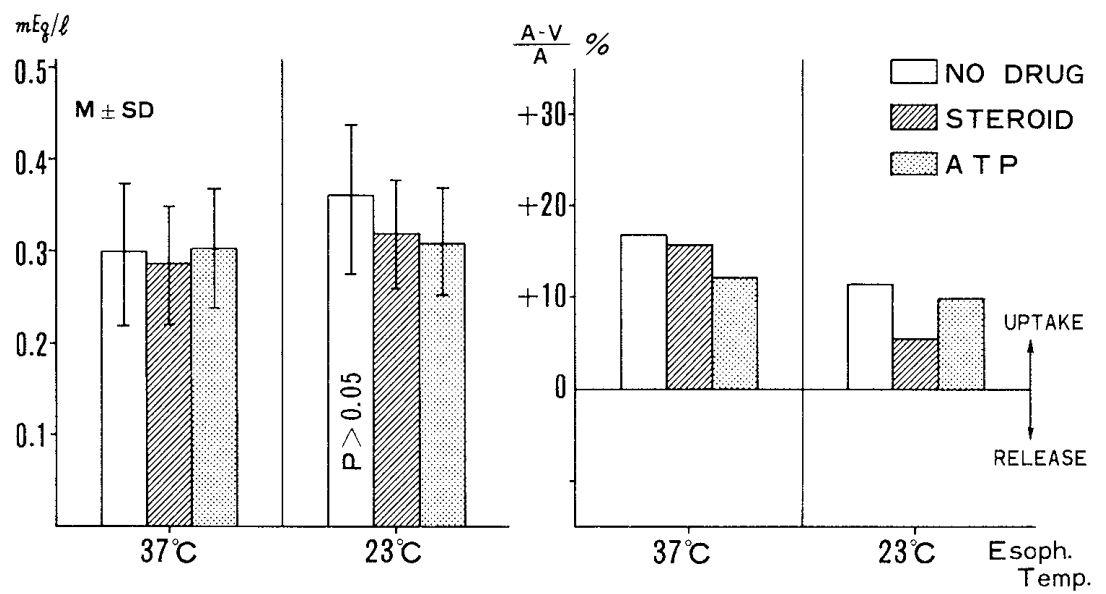

Fig.10. Plasma NEFA (left) and coronary A-V difference ratio of NEFA (right) in hypothermia in each group.

and that at $23^{\circ} \mathrm{C}$, there was no definite difference (Fig. 9).

\section{Plasma NEFA}

Plasma NEFA was $0.34 \pm 0.17 \mathrm{mEq} / 1$ at $37^{\circ} \mathrm{C}$ and $0.36 \pm 0.18$ at $23^{\circ} \mathrm{C}$ in the group I, $0.29 \pm 0.07$ at $37^{\circ} \mathrm{C}$ and $0.29 \pm 0.07$ at $23^{\circ} \mathrm{C}$ in the group II, $0.30 \pm 0.13$ at $37^{\circ} \mathrm{C}$ and $0.31 \pm 0.11$ at $23^{\circ} \mathrm{C}$ in the group III respectively. Namely, plasma NEFA showed no significant change as low as $23^{\circ} \mathrm{C}$ in the condition without heparin in each group. As for myocardial metabolism of NEFA, coronary A-V difference ratio of NEFA showed approximately $15 \%$ uptake at the precooling in each group. While, coronary A-V difference ratio of NEFA except the steroid group still maintained more than $10 \%$ uptake at $23^{\circ} \mathrm{C}$ (Fig. 10).

\section{DISCUSSION}

As for the characteristic change associated with open-heart surgery undergoing surfaceinduced deep hypothermia, metabolic acidosis due to lactacidemia has been generally observed. Moreover, it has been assumed that the mechanism of lactacidemia results from the increase of acid metabolites in the condition of anaerobic glycolysis and the disability to metabolize the acid metabolites in the liver! While, as for the change of coronary blood flow and myocardial oxygen consumption associated with hypothermia, it is reported that oxygen uptake by the myocardium is reduced as temperature falls, however, the rate of reduction in coronary flow is less than that for the entire body, indicating the greater need of oxygen by the heart?, 8 In this study, coronary $\mathrm{A}-\mathrm{V}$ oxygen difference was unchanged as low as $23^{\circ} \mathrm{C}$ because of hyper- ventilation of $\mathrm{FiO}_{2} \quad 100 \%$. Coronary blood flow was reduced $46 \%$ of normal and oxygen uptake by the myocardium was reduced $44 \%$ of normal at $23^{\circ} \mathrm{C}$.

In genral, the heart normally used many substances other than oxygen such as glucose, lactate, pyruvate and fatty acids for energy fuels. From the standpoint of the coronary $A-V$ difference of lactate and pyruvate, lactate and pyrubate uptake by the myocardium as low as $23^{\circ} \mathrm{C}$ was approximately more than $50 \%$ of normal, though myocardial oxygen consumption was reduced $44 \%$ of normal. Moreover, pyruvate dehydrogenase showed no reduction at $23^{\circ} \mathrm{C}$, suggesting the stimulation of ATP production mediated by TCA cycle from lactate and pyruvate as energy fuels in the cardiac muscle. Therefore, it seems that lactate and pyruvate play an important metabolic role in the hypothermic heart.

As for lipid metabolism in the cardiac muscle, fatty acid, especially NEFA supposedly plays an important role9, 10,11 In this study, plasma NEFA showed a trend of slight increase as low as $23^{\circ} \mathrm{C}$, indicating the decrease of peripheral utilization of NEFA. While, the hypothermic heart still used NEFA as energy fuel in the aspect of coronary A-V difference of NEFA at $23^{\circ} \mathrm{C}$.

In starvation, it is reported that blood glucose decreases, while a compensatory increase of NEFA is observed, indicating a reverse correlation between blood glucose and plasma NEFA ${ }^{12,13}$ There is also the reverse correlation between glucose and NEFA in the aspect of myocardial metabolism. On the other hand, in hypothermia, blood glucose showed a significant increase, suggesting a decrease of utilization of 
glucose in the peripheral tissue and a suppression of insulin secretion. However, in the myocardial metabolism of glucose, coronary A.V difference ratio of glucose was 1 to $6 \%$ before the cooling and 0 to $2 \%$ as low as $23^{\circ} \mathrm{C}$. Namely, in this study, glucose uptake by the myocardium was decreased as low as $23^{\circ} \mathrm{C}$.

From the standpoint that hypothermia regarded as a controlled shock, the influence of high dose of corticosteroid ${ }^{14}$ and ATP, 15,16 which are supposed to have antishock effects, upon the carbohydrate and lipid metabolism of cardiac muscle was investigated. In this study, no definite effect of the administration of corticosteroid and ATP on myocardial metabolism of carbohydrate and lipid was observed.

\section{SUMMARY}

In surface-induced deep hypothermia, metabolic acidosis resulting from lactacidemia was observed. In the aspect of myocardial metabolism, the rate of reduction in coronary A-V difference ratio of lactate, pyruvate and NEFA was less than that of coronary flow and myocardial oxygen consumption in the hypothermic heart. Namely, it seems that lactate, pyruvate and NEFA play an important role as energy fuel in the hypothermic heart. On the other hand, myocardial metabolism of glucose was reduced in the hypothermic heart. Moreover, it seems that exogenous corticosteroid and ATP do not influence on the myocardial metabolism of carbohydrate and lipid in the hypothermic heart.

\section{REFERENCES}

1. SHIDA, H.: Pathogenesis and treatment of metabolic acidosis in open-heart surgery under surface-induced deep hypothermia. Jap. J. Surg., 4: 198-203, 1974.

2. SHIDA, H., MORIMOTO, M., SEKI, T., \& INOKAWA, K.: Metabolic changes in surface-induced deep hypothermia combined with cardiopulmonary by pass for cardiac surgery. Jap. J. Surg., 5: 73-83, 1975.

3. RICHTERICH, R.: Clinical chemistry, p.219223, Academic Press, N. Y. 1969.

4. FOLCH, R. M., RUBINSTEIN, D., McGarry, E. E., \& BECK, J. C.: Factors influencing the release of free fatty acids from adipose tissue. Endocrinology 69: $1009-1015,1961$.

5. DUNCOMBE, W. G.: The colorimetric microdetermination of non-esterified fatty acids in plasma. Clin. Chim. Acta. 9: 122-125, 1964.

6. WIELAND, O. H., PATZELT, C., \& LOFFLER, G.: Active and inactive forms of pyruvate dehydrogenase in rat liver. Eur. J. Biochem., 26:426-433, 1972.

7. EDWARDS, W. S., TULUY, S., RUBER, W. E., SIEGEL, A., \& BING, R. J.: Coronary blood flow and myocardial metabolism in hypothermia. Ann. Surg., 139: 275-281, 1954 .

8. GEROLA, A., FEINBERG, H., \& KATZ, L. N.: Myocardial oxygen consumption and coronary blood flow in hypothermia. Am. J. Physiol., 196: $719-725,1959$.

9. BING, R. J., DANFORTH, W. H., \& BALLARD, F. B.: Physiology of the myocardium. JAMA., 172: 438-444, 1960.

10. BALLARD, F. B., DANFORTH, W. H., NAEGLE, S., \& BING, R. J.: Myocardial metabolism of fatty acids. J. Clin. Invest., 39: 717-723, 1960.

11. GOTO, Y.: The fatty metabolism in the heart muscle. Jap. Circ. J., 26: 121-127, 1962.

12. DOLE, V. P.: A relation between non-esterified fatty acids in plasma and the metabolism of glucose. J. Clin. Invest., 35: 150-154, 1956.

13. GORDON, R.S.Jr. \& CHERKERS, A.: Unesterified fatty acid in human blood plasma. J. Clin. Invest., $35: 206-212,1956$.

14. LILLEHEI, R. C., LONGERBEAM, J. K., BLOCH, J. H., \& MANAX, W. G.: The nature of irreversible shock. Ann. Surg., 160: 682-710, 1964.

15. TALAAT, S. M., MASSION, W. H., \& SCHINING, J. A.: The effect of ATP administration in irreversible shock. Surgery, 55: 813-819, 1964.

16. GREEN, H. N. \& STONER, H. B.: The present status of the adenine nucleotides in the bodily response to injury. Brit. Med. J., 2: 805-809, 1950. 